\title{
Mechanical properties of $\mathrm{C} / \mathrm{C}$ composites processed by wet impregnation and P-CVI methods
}

\author{
J. Michalowski $\cdot$ D. Mikociak $\cdot$ K. J. Konsztowicz • \\ S. Blazewicz
}

Received: 7 February 2011/ Accepted: 24 March 2011/Published online: 13 April 2011

(C) The Author(s) 2011. This article is published with open access at Springerlink.com

\begin{abstract}
Wet impregnation with phenolic resin and $\mathrm{P}$-CVI methods were used to manufacture $\mathrm{C} / \mathrm{C}$ composites. The influence of impregnation process of porous 2D carbon fibre substrate with resin and pyrocarbon deposited by CVD technique on mechanical properties of formed composites was studied. The results indicate that using P-CVI method large pores remain in the matrix resulting in lower mechanical strength. This fraction does not undergo any changes during thermal treatment. The flexural modulus of $\mathrm{C} / \mathrm{C}$ composites depends mainly on the type of reinforcing fibres. The values of moduli measured in composites obtained by both methods do not differ significantly. Comparison of two methods of fabrication of $\mathrm{C} / \mathrm{C}$ composite show that much better strengths can be achieved by forming the carbon matrix in solid state.
\end{abstract}

\section{Introduction}

Mechanical properties of $\mathrm{C} / \mathrm{C}$ composites are strongly affected by the type of their constituents as well as by the methods and conditions of their processing. Even the

J. Michalowski

Institute of Nuclear Physics, Krakow, Poland

D. Mikociak · S. Blazewicz $(\bowtie)$

Department of Biomaterials, Faculty of Materials Engineering and Ceramics, AGH University of Science and Technology, Krakow, Poland

e-mail: blazew@agh.edu.pl

\section{K. J. Konsztowicz}

Department of Industrial Engineering, Faculty of Mechanical

Engineering, and IT, University of Bielsko-Biała,

Bielsko-Biała, Poland selection of fibres with superior parameters does not necessarily guarantee achieving advantages in mechanical properties of a final composite. Excessive strength of interface bond is not recommended during the initial processing stage of the composite and may lead to drastic depreciation of its mechanical parameters during following processing stages $[1,2]$. The resistance to interlaminar shear stress determines adequately the strength of fibrematrix interface and at the same time it is the best indicator of good overall mechanical properties of the composite [3, 4]. Hence, much attention is attributed to initial fibre surface preparation in technological studies on processing of $\mathrm{C} / \mathrm{C}$ composites. These issues are largely discussed in monographic works devoted to carbon composites [1-7] as well as in review papers $[8,9]$.

With properly selected reinforcing fibres, after thermal treatment of polymer applied e.g. by liquid impregnation, strongly porous carbonic phase appears in the following process of carbon matrix formation. Methods of liquid impregnation and various modifications of CVD method are being commonly used as basic techniques of densification of porous composite matrix after first thermal treatment of polymer substrate. The principles of both techniques in application to $\mathrm{C} / \mathrm{C}$ composites are well defined and known [10-12], however intensive works are still being carried out related to modification and optimization of the process itself, considering many factors affecting the porous substrate, gas phase carbon precursors, as well as modifications of construction of the reactor itself where the process takes place [11-14].

The majority of published studies concentrate on the appropriate combination of process parameters which would lead to maximum densification of the matrix within possibly shortest time. One of the key issues is the closed porosity formed during first carbonization or the following 
saturation, which does not enable achieving suitably high densities of processed composites [15-17].

During thermal treatment of phenolic resin matrix substrate of the composite processed using liquid impregnation method, this matrix forms as a glass-like carbon. It is highly porous, however, it is impermeable to gases as its pores are of closed nature [17]. Such pores present in the glass-like composite matrix deteriorate its mechanical properties and on the other hand they are difficult to eliminate by means of typical densification processes [1821]. The efficiency of both CVD and liquid impregnation techniques is poor in this case and practically they do not bring about enhancement of mechanical properties. One of the ways to circumvent this problem is the application of intermediate technological step in form of thermal treatment between the densification cycles, which leads to opening of closed porosity due to the build-up of thermal stresses [20, 21].

The introduction of pulsating P-CVI method of densification of porous carbon matrix leads to increased efficiency of densification processes [12, 22]. The final porosity of carbon composites is believed to be determined by both time of infiltration and carbon-carrier gas as well as by the flow rate [23, 24]. The effects of technological parameters on final mechanical properties of carbon composites have also been examined in studies [20, 25].

This study presents the results of comparative study of the effects of application of two basic methods of $\mathrm{C} / \mathrm{C}$ composite processing on their mechanical properties. One type of fibre was used in both cases with the same way of their spatial arrangement within the carbon matrix. The principal goal of the study was the comparison of the efficiency of saturation process on mechanical properties of formed composite microstructures involving multiple impregnation.

\section{Materials and processing methods}

Composite materials processing with use of liquid impregnation of phenolic resin

The following components have been applied in composite sample processing:

- phenol-formaldehyde $(\mathrm{F}-\mathrm{F})$ resin of trade name Nowolak MR, manufactured by Abrasive Works, Krakow, Poland. It was made of $90 \%$ of novolak resin and $10 \%$ of hexamine $\left(\mathrm{CH}_{2}\right)_{6} \mathrm{~N}_{4}$ as hardener.

- carbon fabric made of HM, PAN based carbon fibre M40-3K (by Torayca Manuf.) with surface preparation for epoxy resins. Carbon fibres had the following properties: (a) tensile strength $2.7 \mathrm{GPa}$, Young's modulus: $392 \mathrm{GPa}$, strain to fracture: $0.7 \%$, average diameter: $6.5 \mu \mathrm{m}$, density: $1.81 \mathrm{~g} / \mathrm{cm}^{3}$.

In the first stage of sample manufacturing, the prepregs were made in form of sheets containing carbon fibre fabrics saturated with F-F resin solution. The details of the prepregs preparation, fabrication of polymer/carbon fibres composite and $\mathrm{C} / \mathrm{C}$ samples are described elsewhere [22]. The composites samples of dimensions $10 \times 77 \times 1 \mathrm{~mm}$ were obtained.

Samples obtained after first carbonization had relatively high porosity, reaching $25 \%$. In order to increase their density, four consecutive cycles of impregnation with F-F resin have been applied, each followed by re-carbonization processes. After each impregnation-recarbonization cycle, the appropriate amount of samples were put on a side for further investigation. In the final stage, a part of the samples were subjected to high-temperature treatment, carried out at temperatures of 1,000, 1,450, 1,900 and 2,200 ${ }^{\circ} \mathrm{C}$.

Composites with $\mathrm{F}-\mathrm{F}$ polymer matrix constituting the substrate of $\mathrm{C} / \mathrm{C}$ composite were denoted with symbol (0). The efficiency of impregnation process was assessed by examination of apparent density. The denotation of composite samples after each processing step applied further in this study is defined below:

1. $\mathrm{C} / \mathrm{C}$ composite after carbonization in $1,000{ }^{\circ} \mathrm{C}$,

2. $\mathrm{C} / \mathrm{C}$ composite after first impregnation with $\mathrm{F}-\mathrm{F}$ resin solution in alcohol and second carbonization at $1,000{ }^{\circ} \mathrm{C}$,

3. $\mathrm{C} / \mathrm{C}$ composite after second impregnation with $\mathrm{F}-\mathrm{F}$ resin solution and second re-carbonization at $1,000{ }^{\circ} \mathrm{C}$,

4. composite $\mathrm{C} / \mathrm{C}$ after $3 \mathrm{rd}$ impregnation with $\mathrm{F}-\mathrm{F}$ resin and third re-carbonization at $1,000{ }^{\circ} \mathrm{C}$,

5. the $\mathrm{C} / \mathrm{C}$ composite after 4th impregnation with $\mathrm{F}-\mathrm{F}$ resin and forth re-carbonization at $1,000{ }^{\circ} \mathrm{C}$,

6. $\mathrm{C} / \mathrm{C}$ composite denoted as no. 4 , subjected to additional thermal treatment at $1,450{ }^{\circ} \mathrm{C}$ followed by forth impregnation with $\mathrm{F}-\mathrm{F}$ resin solution and re-carbonization,

7. $\mathrm{C} / \mathrm{C}$ composite denoted as no. 4 , subjected to additional thermal treatment at $1,900{ }^{\circ} \mathrm{C}$, followed by forth impregnation with $\mathrm{F}-\mathrm{F}$ resin solution and re-carbonization,

8. $\mathrm{C} / \mathrm{C}$ composite denoted as no. 4 , subjected to additional thermal treatment at $2,200{ }^{\circ} \mathrm{C}$, followed by forth impregnation with $\mathrm{F}-\mathrm{F}$ resin solution and re-carbonization.

Composite materials processing with pulse P-CVI technique

Carbon fibres of same type as previous one were applied for manufacturing samples with use of this method. 
Technology of sample preparation using the pulse P-CVI method consisted of forming 11 layers of carbon fabric of the size $35 \times 80 \mathrm{~mm}$ into a sheet pack placed in graphite mould. This mould with layers of carbon fabric was placed at the end of vacuum furnace, heated to pyrolysis temperature of $930{ }^{\circ} \mathrm{C}$. The processing of composite samples with use of pulse P-CVI technique was preceded by preliminary experiments aiming at optimization of process parameters. Details of this method were given in our previous study [22].

After the first series of 5,000 pulses, the $\mathrm{C} / \mathrm{C}$ composite plate was removed from graphite mould and it was subjected to 5,000 pulses of impregnation without graphite lining. Samples after this first series of impregnation were designated with number (1). They were subjected to further processing cycles consisting of series of P-CVI impregnations with 5,000 pulses each and thermal treatment as a final stage. After each cycle, the mechanical parameters of obtained composites as well as their density and porosity were determined.

The second phase consisted of impregnations of samples from phase (1) with three series of 5,000 pulses each until 25,000 pulses have been achieved. At this point of treatment, part of samples were put on a side for further mechanical and thermal properties testing and they were designated samples number 2 . The third phase of thermal treatment of composites used only samples from phase (2) and the batch was divided into four parts. Each of them was obtained in different temperature: 1,000, 1,450, 1,900 and $2,200{ }^{\circ} \mathrm{C}$. After high temperature, thermal treatment of all these samples have been impregnated with 5,000 pulses P-CVI. After this final stage of thermal treatment and impregnation, samples have achieved 30,000 pulses of impregnation and they were designated with numbers 3-6, according to the temperature of thermal treatment. Composite samples after various processing stages were subjected to examination of their porosity and mechanical properties.

\section{Methods of properties' examination}

Apparent density has been examined using standard hydrostatic technique. This value was calculated as the average taken from three measurements. Porosity and pore size distribution in composite samples after specific processing steps was determined at different stages with use of mercury porosimeter (model Po-2000), with mercury pressure varying from 12 to $200 \mathrm{MPa}$. Based on these measurements, the pore size distribution in composites as well as average pore radius and total porosity of samples have been determined. Flexural strength and modulus were measured according to PN-EN-ISO 178. A universal testing machine Zwick (model 1435) was utilized for 3-point bending mode with a crosshead speed of $2 \mathrm{~mm} /$ min.

Samples examined had the dimensions: $1.0 \times 10 \times$ $70 \mathrm{~mm}$.

The interlaminar shear stress (ILSS) was also determined in 3-point bending at the testing span of the samples equal to $10 \mathrm{~mm}$. Five samples of each type were used for flexural tests and the average values were reported.

\section{Results and discussion}

C/C samples obtained with liquid impregnation method

The effects of impregnation of porous carbon matrix and consecutive thermal treatment on the density of samples after each processing step are show in Fig. 1. This figure shows variations of density and shrinkage of composite samples due to impregnation and re-carbonization as well as due to additional thermal treatment at different temperatures. Apparent density of initial composite made of carbon fibres and polymer matrix (phenol-formaldehyde resin) is also shown. Open porosity of this composite determined using mercury porosimetry does not exceed $1.85 \%$.

First carbonization (no 1) is accompanied by substantial increase of open porosity amounting to $23 \%$. The analysis of pore size distribution diagram (not shown here) indicates that after carbonization a new fraction of pores is being created in the size range of one to a few dozens of micrometres. This fraction is present in all phases of technological process. As it can be seen from this figure, the effect of densification of carbon matrix by consecutive

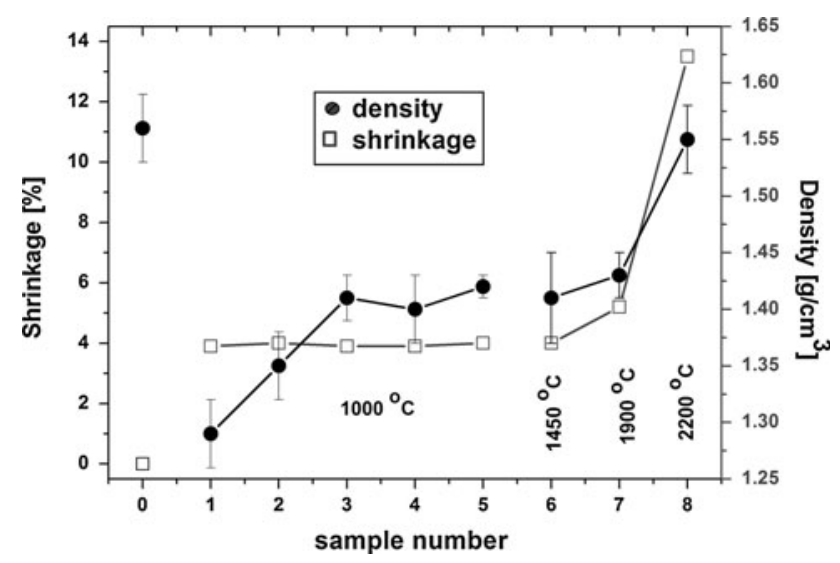

Fig. 1 Variation of apparent density and shrinkage of composite samples with number of impregnations in function of temperature. Note: Sample denoted 0 is the fibre/polymer composite, samples 1-5 are $\mathrm{C} / \mathrm{C}$ samples after consecutive impregnations and carbonizations, samples $6-8$ are materials after additional thermal treatment 
impregnation and re-carbonization at different temperatures can be noticed until the fourth cycle, after which the impregnation is no more efficient. A considerable increase of apparent density of samples can be also observed as transversal shrinkage of the sample occurring due to thermal treatment at temperatures up to $2,200{ }^{\circ} \mathrm{C}$.

Transversal shrinkage measured on the samples amounts to $14 \%$. It may be accepted therefore that at higher temperatures the process of carbon re-crystallization occurs, leading to density increase of the composite. The effect of impregnation seems to be of secondary importance here and this result indicates that secondary high temperature treatment does not lead to opening of closed porosity, but it only increases the measured density related to structural and microstructural changes of the matrix itself. The value of open porosity remains at the same level as in the samples processed at lower temperatures and subjected to consecutive stages of impregnation.

Variations of ILSS parameter resulting from varying conditions of thermal treatment and subsequent cycles of impregnation and re-carbonization are shown in Fig. 2. Following impregnation and re-carbonization, ILSS increases to about $15 \mathrm{MPa}$ after which it remains at this constant level. This figure shows that the value of ILSS is primarily affected by initial stages of impregnation. Further thermal treatment at high temperatures $\left(1,450-2,200{ }^{\circ} \mathrm{C}\right)$ does not affect this parameter. Shear strength of the composite significantly increases with the number of impregnations.

Bending strength and flexural modulus, similar to ILSS increase only to certain point during the process, as it is shown in Fig. 3. Composite density increase results from the reduction of porosity as well as the interplanar distance of carbonized matrix. The mercury porosimetry results

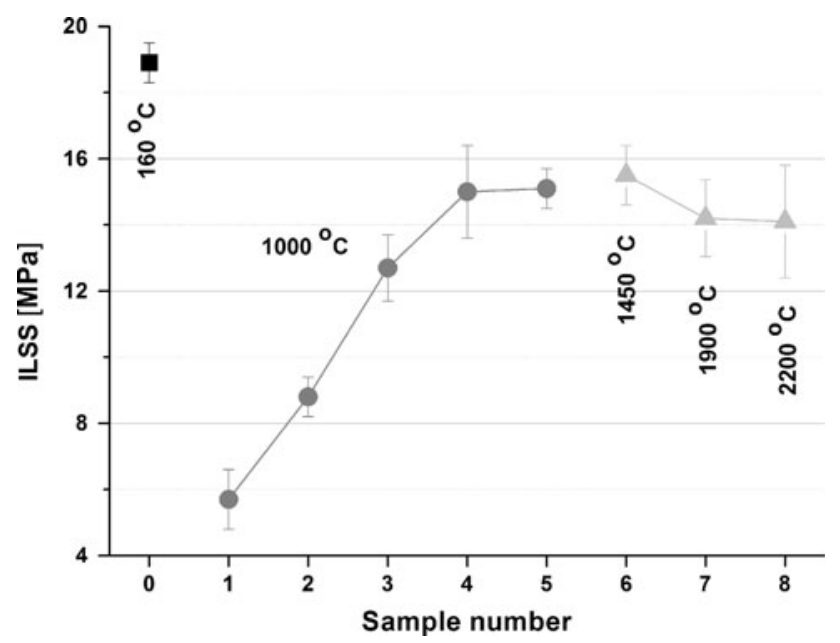

Fig. 2 The ILSS variations resulting from subsequent cycles of impregnation and re-carbonization (samples 1-5) and additional thermal treatment (samples 6-8) of $\mathrm{C} / \mathrm{C}$ composites indicate that the content of both open and total porosity decrease, particularly during the first stages of impregnation, giving the largest increments in strength. However, despite the reduction of porosity, the increase of density above certain level does not bring about further increase of strength. These relationships suggest that the strength of $\mathrm{C} / \mathrm{C}$ composite depends in more complex ways on such parameters as apparent density, porosity, ILSS and temperature. It seems that the temperature does not affect directly the strength, although it affects the increase of apparent density. The strength and flexural modulus increase to certain level despite further increase of apparent density. The strength is being even slightly reduced. Higher value of flexural modulus after high temperature treatment can be observed as compared to polymer matrix composite. This may result from improvement of elastic properties of the matrix itself after thermal treatment at $2,200{ }^{\circ} \mathrm{C}$. Fibres as material's components do not vary their structure at applied temperature conditions, therefore any changes of their elastic properties can be excluded.

Microphotographs of fracture surfaces of $\mathrm{C} / \mathrm{C}$ composites after various stages of impregnation are shown in Fig. 4a, b.

As shown in Fig. 4a, after first carbonization, the composite sample is strongly porous with defects of the order of $50 \mu \mathrm{m}$. After fourth impregnation-carbonization cycle (Fig. 4b), the sample has visibly less defects, however, even in this case, singular large voids can be seen of similar size to initial samples. Despite observed increase of apparent density of the composite, its strength does not increase due to the presence of these large defects within the matrix.

This research showed that mechanical properties of $\mathrm{C} / \mathrm{C}$ composites processed from polymer precursor are being

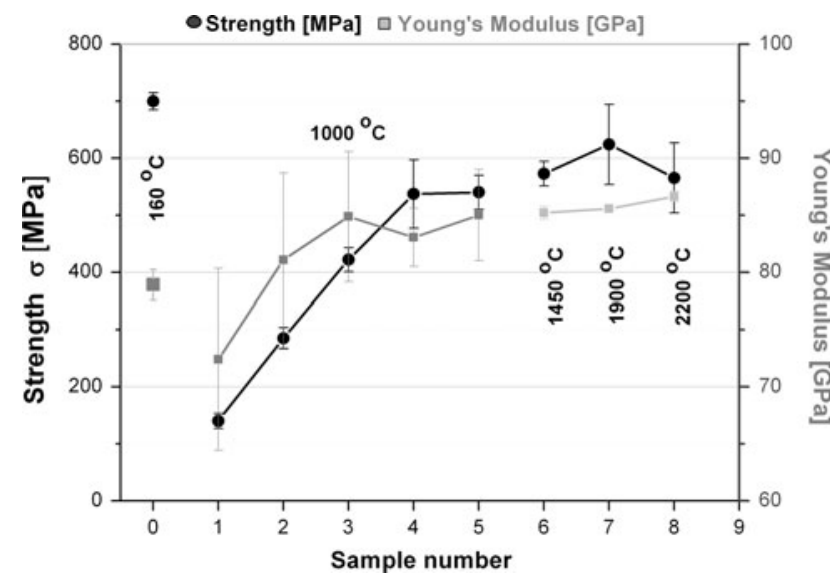

Fig. 3 Variations in bending strength and flexural modulus of $\mathrm{C} / \mathrm{C}$ composites resulting from application of cyclic stages of impregnation and re-carbonization as well as additional thermal treatment applied in processing. Points at $160{ }^{\circ} \mathrm{C}$ represent the composite with resin matrix 

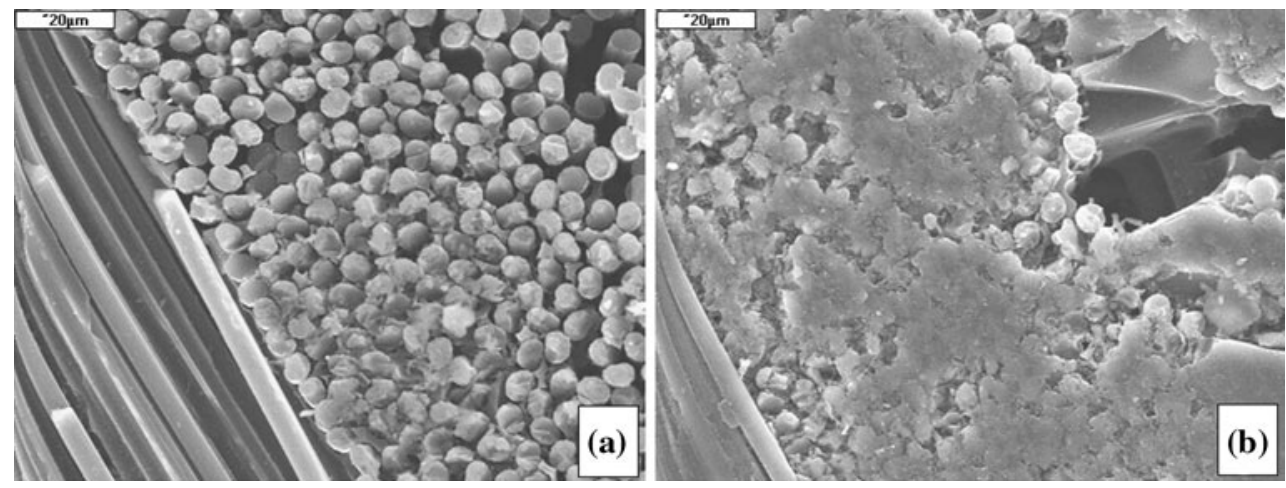

Fig. 4 The SEM photomicrographs of composite fracture surface after first carbonization (a) and after multiple impregnation and re-carbonization $(\mathbf{b})(\times 1,000)$

shaped mainly during the carbonization process and multiple impregnation, re-carbonization cycles. This process takes place at $1,000{ }^{\circ} \mathrm{C}$. Strength increases during this process particularly visibly as after third cycle it obtains the fourfold value of that during the first carbonization. Further stages of composite processing involving thermal treatment are not as effective in regard to mechanical properties. The increase of the density of $\mathrm{C} / \mathrm{C}$ composites above $1,000{ }^{\circ} \mathrm{C}$ is due to decrease of sample volume, which is related to recrystallization of the matrix material.

The interlaminar shear strength distinctly affects the mechanical properties. Estimates based on reduced rule of mixtures for brittle matrix composite indicate relatively good ratio of utilization of mechanical properties of carbon fibres used in experiments. Increase in ILSS value in the phase of initial impregnation and re-carbonization may be explained by increase in effective contact surface between fibre and matrix as the density increases and this is advantageous for increase of effective interaction force between the components. The contribution of matrix to enhancement of mechanical properties consists mostly of reduction of porosity volume (first cycles of impregnation and recarbonization), while its re-crystallization (effects of thermal treatment on changes of structural parameters) does not have significant effect on mechanical properties.

\section{$\mathrm{C} / \mathrm{C}$ composite processed using P-CVI method}

Figure 5 demonstrates the results of processing with use of P-CVI method on sample densification. The runs represent the effect of number of pulses during impregnation phase on changes of apparent density and total porosity of $\mathrm{C} / \mathrm{C}$ composite, which had its deposition phase performed at $930{ }^{\circ} \mathrm{C}$ (points $0-30$ ) and subjected to additional heat treatment at $1,450,1,900$ and $2,200{ }^{\circ} \mathrm{C}$ (points 35-45).

Since the time of single pulse and total number of P-CVI pulses are known, horizontal axis expresses also the duration of impregnation time. Initially the porous scaffold is made of sheets of carbon fibre fabric with density of $0.83 \mathrm{~g} / \mathrm{cm}^{3}$, and porosity of the order of $55 \%$. After first stage of impregnation (10,000 pulses), the preform is still highly porous, as documented by the SEM (Fig. 6a). The size of defects being formed at junctions of carbon fibre yarns exceeds $250 \mu \mathrm{m}$. The apparent density of samples after initial impregnation (10,000 pulses) has the value of around $1.23 \mathrm{~g} / \mathrm{cm}^{3}$, while open porosity as determined by mercury porosimetry reaches $47 \%$. Pore size analysis indicates that these composites still contain the fraction of pores of the sizes exceeding $50 \mu \mathrm{m}$.

Defects of this size were never present in $\mathrm{C} / \mathrm{C}$ composites processed by liquid impregnation method. The density of composites systematically increases following impregnation cycles and finally reaches the value of $1.42 \mathrm{~g} / \mathrm{cm}^{3}$. Figure 5 indicates that porosity after P-CVI impregnation is much higher than in the case of samples processed by liquid impregnation and equals $23 \%$.

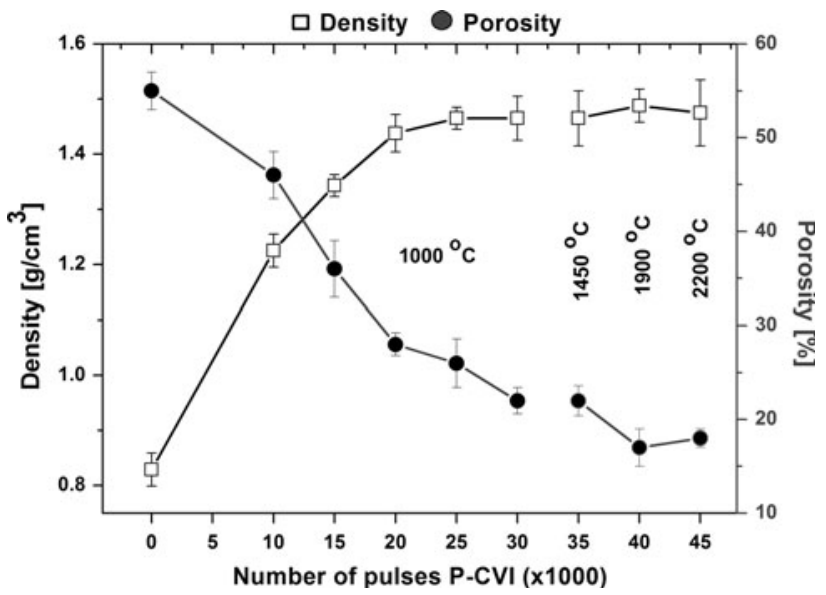

Fig. 5 Variations of apparent density and total porosity of $\mathrm{C} / \mathrm{C}$ composite in function of number of impregnation pulses applied to carbon preform. Point $(0)$ on $X$-axis refers to density and porosity of unimpregnated carbon fibre perform 

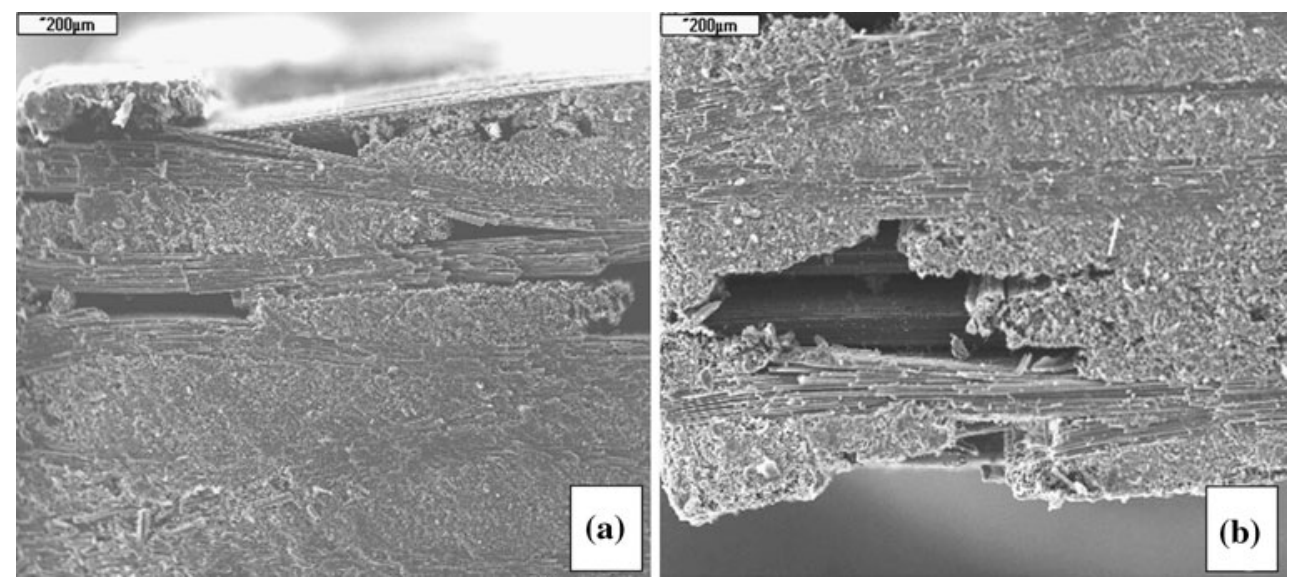

Fig. 6 SEM photomicrograph of a cross-section of 2D C/C composite after 10,000 pulses $(\times 100)$ and $\mathbf{b}$ composite sample after impregnation with use of P-CVI method $(30,000$ pulses $)$ at $1,000{ }^{\circ} \mathrm{C}(\times 100)$

The SEM microphotograph of cross section of composite sample after impregnation (Fig. 6b) shows the presence of defects of the size of the order of $250 \mu \mathrm{m}$ situated mostly in fibre yarn interlaces. It can be assumed that impregnation process using the P-CVI method leads to filling small pores and formation of stiff scaffolding made of microcomposite areas of the type "carbon fibre-pyrocarbon" which are bound also with pyrocarbon within contact areas. The spaces within interlaces remain practically unchanged and they are responsible for mechanical performance of composites.

As shown by Fig. 5, changes of density accompanying after subsequent thermal treatment from 1,450 to $2,000{ }^{\circ} \mathrm{C}$ and pulse impregnation are not significant, much smaller than in the case of impregnation with use of previously described wet impregnation method. Simultaneously, the decrease of porosity can be observed to the level of $17 \%$. Since pyrocarbon matrix belongs to a group of carbon materials prone to graphitization, it undergoes easily the re-crystallization leading to increased level of structural ordering.

The analysis of pore size distribution indicates that the effect of decrease of average pore size cannot be noticed. Macropore fraction $(250 \mu \mathrm{m})$ remains in composite samples after all technological steps have been completed.

Figure 7 shows the variation of interlaminar shear strength in composite samples impregnated with use of P-CVI method. It can be seen that ILSS doubles after impregnation as compared to initial samples. The absolute values are, however, lower than obtained in composites made of polymer precursor. Thermal treatment of composites to temperature of $2,200{ }^{\circ} \mathrm{C}$ brings about $20 \%$ decrease of ILSS value compared to maximum value. Corresponding changes in bending strength and flexural modulus are shown in Fig. 8.

Composites processed using the P-CVI method show poorer mechanical properties as compared to composites

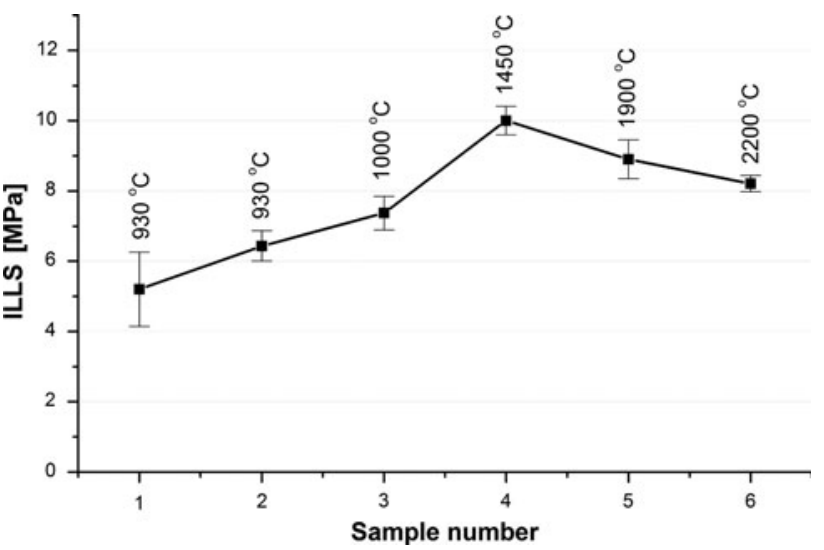

Fig. 7 The ILSS variations resulting from subsequent cycles of impregnation and re-carbonization (samples 1-5) and additional thermal treatment (sample 6 ) of $\mathrm{C} / \mathrm{C}$ composites

obtained by previously described polymer precursor method. After the first phase of impregnation, bending strength of $\mathrm{C} / \mathrm{C}$ composite obtained by P-CVI method is more than three times lower than strength of composites processed by the prepreg method. The strength of the composite samples obtained by P-CVI method increases to $1,900{ }^{\circ} \mathrm{C}$ after thermal treatment and quite good correlation between the strength changes and variations of ILSS parameter was obtained here. Improving bonding between the matrix and fibres brings about increase of bending strength of $\mathrm{C} / \mathrm{C}$ composite and these changes in the phase of high-temperature treatment can be attributed to small decrease of porosity (about 6\%). The plot in Fig. 8, representing the effects of pulse impregnation and thermal treatment, suggests significant contribution of temperature to strength increase. The effects of pulse impregnation on flexural modulus is even more pronounced than in the case of strength, although the variations of this parameter during impregnation and high temperature treatment are less significant, varying from 70 to $80 \mathrm{GPa}$. 


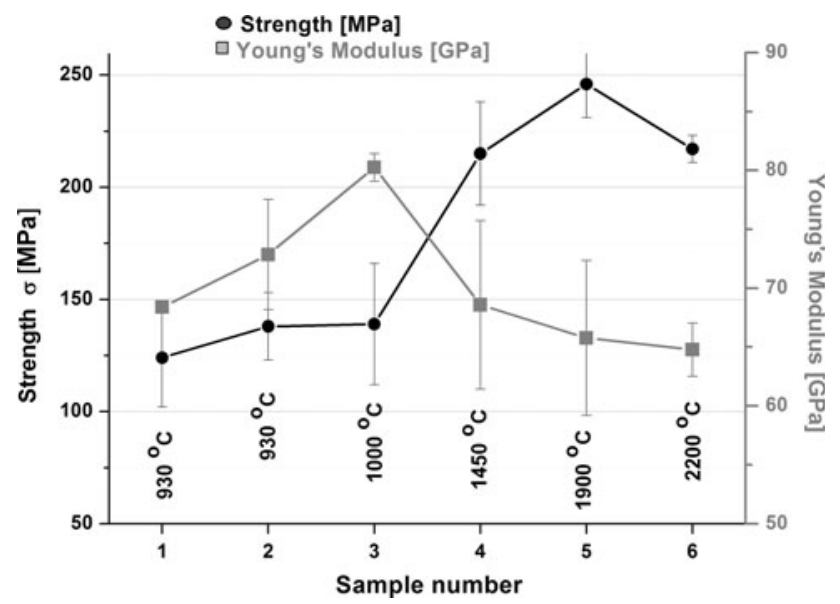

Fig. 8 Changes in strength and flexural modulus of $\mathrm{C} / \mathrm{C}$ composite processed by P-CVI method (points 1 and 2) and additional thermal treatment (points 3-6)

Comparison of the values of modulus of elasticity of C/C composites processed by P-CVI method and the prepreg method indicate that measured differences are less pronounced than in the case of bending strength. Flexural modulus of composites processed using the P-CVI method is some $20 \%$ lower than that obtained with use of prepreg technique. These lower values of mechanical parameters of composites processed via CVD method can be explained on the basis of analysis of pore size distribution. Pyrolytic carbon obtained by P-CVI technique is characterized by better mechanical properties than carbon obtained by solid state pyrolysis of polymer precursor as well as isotropic and mesophase tar pitch. This is due to mechanism of carbon crystallization itself in P-CVI method as well as comparison of properties of components of carbon composite matrices. Irrespective of that, mechanical properties of $\mathrm{C} / \mathrm{C}$ composites with pyrocarbon matrix are definitely lower than $\mathrm{C} / \mathrm{C}$ composites obtained with use of prepreg method. Both types of composites examined in this study are based on the same type of carbon fibre and have similar values of apparent densities. Since the $\mathrm{C} / \mathrm{C}$ composite is made of two phases of different structure and microstructure, the apparent density is a resultant value of densities of both combined phases. Considerably higher open porosity is the reason for much lower strength of $\mathrm{C} / \mathrm{C}$ composite processed by P-CVI method. Composites obtained with use of this technique are made of carbon fabrics separated from each other by strongly defectuous pyrocarbon matrix, bonding carbon yarns and having large voids in yarns' interlacings. These voids remain practically unaffected during all technological processes (impregnation, thermal treatment).

This study of composites obtained by P-CVI method shows that this processing technique is effective enough to ensure high densification of the matrix. However, this technique has one important advantage in comparison to liquid impregnation, namely it allows to avoid shrinkage unwanted during formation of carbon matrix. On the other hand, it is known that such matrix shrinkage occurs during thermal treatment of polymer precursors of matrix materials, including F-F resin. Since during the first phase of impregnation of carbon preform with carbon from gas phase the shrinkage of the matrix does not take place, it may be suggested that the P-CVI method should be applied during the first stage of composite processing. Subsequent steps of composite impregnation should be performed via liquid impregnation using the F-F resin. Such combination of both techniques should allow for much better densification of porous matrix and improvement of mechanical properties of $\mathrm{C} / \mathrm{C}$ composite.

\section{Conclusions}

- Comparison of two methods of fabrication of $\mathrm{C} / \mathrm{C}$ composite shows that much better strengths can be achieved by forming the carbon matrix in solid state.

- The principal reason for lower mechanical properties of composites processed using P-CVI method are the conditions of forming of pyrolytic carbon causing formation of large pores. This fraction does not undergo any change during thermal treatment.

- The flexural modulus of $\mathrm{C} / \mathrm{C}$ composite depends mainly on the type of reinforcing fibres used and the values of modulus of elasticity measured in composites processed by two distinct methods do not differ significantly.

- Mechanical properties of $\mathrm{C} / \mathrm{C}$ composite processed from polymer precursor are being formed in the stage of multiple impregnation and re-carbonization.

- The results of this study show that secondary graphitization does not open closed porosity for impregnation process. The increase of density results from structural and microstructural changes of the matrix.

Acknowledgements This work was financed by the Faculty of Materials Engineering and Ceramics, Statute Founds, project no. 11.11.160.801

Open Access This article is distributed under the terms of the Creative Commons Attribution Noncommercial License which permits any noncommercial use, distribution, and reproduction in any medium, provided the original author(s) and source are credited.

\section{References}

1. Savage G (1993) Carbon-carbon composites, 1st edn. Chapman and Hall, London

2. Tzeng SS, Lin WC (1999) Carbon 37:2011

3. Jin Z, Zhang Z, Meng L (2006) Mater Chem Phys 97:167 
4. Anand K, Gupta V (1995) Carbon 33:739

5. Takano S, Uruno T, Kinjo T et al (1993) J Mater Sci 28:5610. doi:10.1007/BF00367837

6. WCh Chang, Ma ChChM, Taib NH et al (1994) J Mater Sci 29:5859. doi:10.1007/BF00366868

7. Muller M, Beinborn KM, Huttinger KJ (1995) Carbon 33:1043

8. Chen T, Liao J, Liu G et al (2003) Carbon 41:993

9. Tzeng SS, Chr YG (2002) Mater Chem Phys 73:162

10. Ko TH, Kuo WS, Tzeng SS (2003) Compos Sci Technol 63:1965

11. Delhaes P (2002) Carbon 40:641

12. Dupel P, Bourrat X, Pailler R (1995) Carbon 33:1193

13. Lavenac J, Langlais F, Feron O et al (2001) Compos Sci Technol 61:339

14. Lucas P, Marchand A (1990) Carbon 28:207
15. Benzinger W, Becker A, Huttinger J (1996) Carbon 34:957

16. Blanco C, Casal E, Granda M et al (2003) J Eur Ceram Soc 23:2857

17. Fitzer E, Shatter W, Yamade S (1969) Carbon 7:643

18. Chen-Chi M, Tai NH, WCh Chang et al (1996) Carbon 34:1175

19. Feron O, Langlais F, Naslain R et al (1999) Carbon 37:1343

20. Zaldivar JR, Rellic GS (1995) J Am Ceram Soc 78(3):623

21. Glogar P, Manocha LM, Fott P (1996) Carbon 34:1343

22. Michalowski J, Mikociak D, Konsztowicz KJ et al (2009) J Nucl Mater 393:47

23. Blazewicz S, Piekarczyk J, Chlopek J et al (2002) Carbon 40:721

24. Vaidyaraman S, Lackey WJ, Agrawal PK et al (1996) Carbon 34:347

25. Fitzer E (1987) Carbon 25:163 